\title{
REVIEW
}

\section{Acute myocardial infarction in young adults: causes and management}

\author{
S Osula, G M Bell, R S Hornung
}

Postgrad Med J 2002;78:27-30

The case report in this review illustrates an acute myocardial infarction in a young adult probably due to arterial thrombosis that can be attributed to a hypercoagulable state resulting from the nephrotic syndrome. Although rare, acute myocardial infarction should be considered in young adults presenting with chest pain. A detailed clinical history may help to identify the aetiology, and guide subsequent management, but diagnostic coronary angiography is essential. Careful risk factor modification and treatment of the underlying cause should reduce the incidence of recurrent cardiac events.

See end of article for authors' affiliations

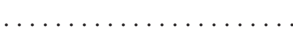

Correspondence to: Dr S Osula, Aintree Cardiac Centre, University Hospital Aintree, Lower Lane, Liverpool $\mathrm{L9}$ 7AL,

UK; sergeosula@ tinyonline.co.uk

Submitted 11 May 2001 Accepted 24 July 2001
A cute myocardial infarction is rare in teenagers and young adults. The pathophysiology of their infarcts is varied but not usually due to atherosclerotic plaque rupture except for those with genetically predetermined or familial hyperlipidaemias. Appropriate treatment has to be adapted from adult management protocols, as there are no controlled trials to guide early treatment of myocardial infarction in this age group.

\section{CASE REPORT}

A 16 year old boy presented to the emergency room with a 30 minute history of severe central, crushing chest pain, radiating down his left arm and associated with sweating, nausea, and breathlessness. He had never previously experienced chest pain at rest or on exertion. At the age of 5 he had meningiococcal septicaemia and meningitis from which he recovered without any long term sequelae. He was diagnosed as having nephrotic syndrome secondary to membranoproliferative glomerulonephritis at the age of 8 years and was started on immunosuppressive therapy (azathioprine and prednisolone). He had stopped taking his prednisolone a week before presentation. He was also taking enalapril and nifedipine for secondary hypertension. He was a nonsmoker and did not have a family history of ischaemic heart disease.

At presentation, he was pale and sweaty with a tachycardia of 110 beats/min. His blood pressure was raised at 190/110 mm Hg. There was no peripheral oedema and all peripheral pulses were present. His heart sounds were normal and there were no signs of heart failure. A 12 lead electrocardiogram (ECG) showed ST segment changes of an acute inferior myocardial infarction. His serum creatine kinase peaked at 2500
U/l. Total cholesterol concentration was raised at $7.7 \mathrm{mmol} / \mathrm{l}$. Urea and creatinine were normal but his serum albumin was low $(19 \mathrm{~g} / \mathrm{l})$, with a total protein of $42 \mathrm{~g} / \mathrm{l}$ and globulins of $23 \mathrm{~g} / \mathrm{l}$. He had a marked proteinuria on dipstick testing throughout his hospital stay. There was a transient leucocytosis of $25 \times 10^{9} / \mathrm{l}$, which returned to normal within three days, and a persistent moderate thrombocytosis of $740 \times 10^{9} / 1$. Antithrombin III, and protein $\mathrm{C}$ and $\mathrm{S}$ activity were within the normal range. The $\mathrm{C} 3$ component of compliment was low $0.23 \mathrm{~g} / \mathrm{l}(0.70-1.70)$ as was his IgG $5.21 \mathrm{~g} / \mathrm{l}$ $(6.13-15.5)$. The rest of his serum immunoglobulins were normal with no evidence of a paraprotein band on electrophoresis. Other immunological indices including antinuclear antibody, antineutrophil cytoplasmic antibody, and antiglomerular basement membrane antibody were negative.

His raised blood pressure was controlled with intravenous atenolol and nitrates. Thrombolysis was instituted with recombinant tissue plasminogen activator followed by intravenous heparin. Post-thombolysis ECG recordings showed complete resolution of his ST segment elevation and new Q-waves in the inferior leads. Echocardiography revealed moderate concentric left ventricular hypertrophy with a hypokinetic inferior wall. Before discharge he underwent a submaximal exercise tolerance test that was negative and his subsequent hospital stay was uneventful. At the time of discharge he was taking atenolol, aspirin, azathioprine, and prednisolone. Coronary angiography was carried out two weeks after discharge and showed normal appearances of his coronary arteries. He has since remained well and asymptomatic.

\section{CAUSES AND MANAGEMENT OF MYOCARDIAL INFARCTION IN YOUNG ADULTS}

Myocardial infarction in young adults can be broadly divided into two groups, those with angiographically normal coronary arteries and those with coronary artery disease of varying aetiology. There is significant overlap in pathophysiology between these two groups.

\section{Angiographically "normal" coronary arteries}

The pathophysiology of myocardial infarction in the presence of "normal" coronary arteries

Abbreviations: ECG, electrocardiogram; PTCA, percutaneous transluminal coronary angioplasty 
remains unclear but can be explained on the basis of coronary artery thrombosis, embolisation, spasm, or a combination of these processes. Coronary thrombosis can be seen in hypercoagulable states such as in the nephrotic syndrome, antiphospholipid syndrome, and protein $S$ and factor XII deficiencies. ${ }^{1-4}$ Coronary embolisation is rare but has been reported with endocarditis usually affecting the aortic valve. ${ }^{5}$ Coronary artery spasm causing myocardial infarction is recognised with both the recreational and therapeutic use of cocaine.$^{67}$ Coronary artery spasm has also been reported as the likely mechanism of infarction associated with alcohol binges and amphetamine use..$^{8-10}$

\section{Hypercoagulable states}

Nephrotic syndrome

Proteinuria associated with the nephrotic syndrome results in the loss of low molecular weight proteins, which in turn alters the concentration and activity of coagulation factors. Thus factors IX, XI, and XII are decreased due to urinary excretion. ${ }^{11}$ As the liver tries to compensate for the hypoalbuminaemic state, there is an increased synthesis of factors II, VII, VIII, X, XIII, and fibrinogen resulting in raised blood levels. ${ }^{11-13}$

Antithrombin III is a coagulation inhibitor that has a direct correlation with serum albumin in the nephrotic syndrome. Significant reductions in antithrombin III are observed with plasma albumin concentration below $20 \mathrm{~g} / \mathrm{l} .{ }^{14}$ Protein C is a vitamin $\mathrm{K}$ dependent coagulation inhibitor that acts on coagulation factors V and VIII while protein $\mathrm{S}$ is a cofactor of activated protein C. Neither of these factors has been clearly implicated in arterial thrombosis in the nephrotic syndrome."

The fibrinolytic system is also affected, with decreased concentrations of plasminogen and raised levels of plasminogen activator. ${ }^{15}{ }^{16}$ There is evidence of decreased fibrinolytic activity with hypertriglyceridaemia, which often occurs in the nephrotic syndrome. ${ }^{17}$

The extent of alterations in the levels of all the proteins mentioned above correlate with the degree of hypoalbuminaemia. A serum albumin of less than $25 \mathrm{~g} / \mathrm{l}$ is a significant risk factor for combined arterial and venous thrombosis in the nephrotic syndrome. ${ }^{18}$ Other factors that contribute to the hypercoagulable state are a thrombocytosis and increased platelet aggregation and adhesiveness. Platelet hyperaggregability correlates with serum cholesterol concentrations. ${ }^{19} 20$

Many of these abnormalities were evident in our patient and may have caused coronary thrombosis without atherosclerotic plaque rupture.

\section{Antiphospholipid syndrome (Hughes' syndrome)}

Arterial and venous thrombosis is a prominent feature of this syndrome together with antiphospholipid antibodies and miscarriages of pregnancy. ${ }^{21}$ Antiphospholipid antibodies are associated with autoimmune diseases such as systemic lupus erythematosus, but when they occur in isolation, this is known as primary antiphospholipid syndrome. The main antiphospholipid antibodies implicated in thrombosis and atherosclerosis are the anticardiolipin antibody, the lupus anticoagulant, and IgG antibodies against plasma phospholipid-bindidng proteins such as $\beta_{2}$-glycoprotein I and prothombin. $^{22}{ }^{23}$

Cardiac complications include myocardial infarctions and a high prevalence of valvular abnormalities of varying severity. ${ }^{24-26}$ It is postulated that the valvular damage is secondary to repeated thrombosis on normal valves that heal by scarring and valve distortion. There is an association between the presence of antiphospholipid antibodies in patients with intermittent claudication and young adults who survive a myocardial infarction. ${ }^{37}$ The mechanism for thrombosis in this syndrome is complex and not well understood. A mild thrombocytopenia is a common finding in antiphospholipid antibody syndrome, though this does not seem to corre- late with thrombosis. ${ }^{28}$ However, there is in vitro evidence that the anticardiolipin antibody increases platelet adhesiveness. ${ }^{29}$ It is possible that the antiphospholipid antibodies predisposes to premature atherosclerosis compounding the risk for infarction with this syndrome. ${ }^{27} 3031$

\section{Coronary artery spasm}

Cocaine-Coronary artery spasm is probably the predominant mechanism for myocardial infarction with the use of cocaine. Cocaine has been associated with angina, myocardial infarction, tachyarrhythmias and bradyarrhythmias, sudden cardiac death and myocardial contraction bands, which probably act as a substrate for arrhythmias. ${ }^{632}$ The cardiac effects of cocaine are mediated via four main pathways ${ }^{33}{ }^{34}$ : (1) increased myocardial oxygen demand due to an acute rise in systemic blood pressure and heart rate; (2) coronary vasoconstriction caused by its $\alpha_{1}$-adrenergic properties and calcium dependent direct vasoconstriction; (3) endothelial dysfunction which predisposes to vasoconstriction and thrombosis; and (4) promotion of arteriosclerosis. ${ }^{35} 36$

\section{Coronary embolisation}

Endocarditis-Embolisation of septic vegetations from the aortic and mitral valves causing myocardial infarction has been reported ${ }^{37}$ Left sided infective endocarditis is common in intravenous drug abusers and usually affects morphologically abnormal valves. ${ }^{38}$ Vegetations may be non-septic as seen in the antiphospholipid antibody syndrome and systemic lupus endocarditis. Such vegetations resolve with anticoagulation. ${ }^{5}$ Thrombotic microembolisation causing myocardial infarction has been reported with bacteraemia in the absence of endocarditis. ${ }^{39}$

\section{Myocardial bridging}

This is a congenital anomaly in which a coronary artery is embedded within a tunnel of the subepicardial myocardium or has a band of myocardium overlying it. This can impede blood flow during systole that can persist during diastole resulting in myocardial ischaemia, which has been associated with myocardial infarction. Traditionally treatment involved surgical splitting of the band but there are now reports of successful treatment by stent implantation. ${ }^{40}$

\section{Angiographically "abnormal" coronary arteries}

The definition of normality is arbitrary, as we know that angiographically normal looking coronary arteries can have significant atherosclerotic plaque burden when assessed using intracoronary ultrasound.

\section{Accelerated atherosclerosis}

The prevalence of advanced coronary atheroma in young adults is not well established. In an autopsy study of 760 victims of accidents suicides or homicides aged 15-34 years, advanced coronary atheroma were seen in $2 \%$ of males aged $15-19$ years (none in women). In the $30-34$ age group, $20 \%$ of men and $8 \%$ of women had advanced coronary atheroma. ${ }^{41}$

Mutations in the gene encoding the low density lipoprotein receptor produces familial hypercholesterolaemia, an autosomal dominant disorder clinically characterised by high serum cholesterol (low density lipoprotein fraction) concentrations, xanthomas, and premature atherosclerosis. ${ }^{42}$ Various other lipid fractions and hyperhomocysteinaemia are implicated in premature atherosclerosis and myocardial infarction. ${ }^{43}{ }^{44}$ Other risk factors include smoking, hypertension, insulin resistance, obesity, and a family history of premature cardiovascular events. ${ }^{45}$

\section{Spontaneous dissections}

Spontaneous coronary artery dissection is a rare cause of myocardial infarction. It is a condition with greater prevalence in young women, particularly in the peripartum or early postpartum period. It also has been described in association with 
atherosclerotic plaque and in an idiopathic group of patients. The left anterior descending artery is often involved, but there are reports of multiple vessel involvement. The pathophysiological characteristics remain unclear. Unlike atherosclerotic intimal dissection, the dissection plane lies within the media or between the media and adventitia. Often the diagnosis is made at autopsy. Treatment options range from conservative management, bypass surgery, or angioplasty and stenting. ${ }^{46}$

Aneurysms, ectasia, and anomalous origin of coronary arteries

Coronary artery aneurysms are congenital or acquired secondary to Kawasaki's disease in childhood. ${ }^{47}$ They have been linked to myocardial infarction in young adults, though the mechanism is not understood. ${ }^{48}$ Anomalous origins of either left or right coronary arteries have been associated with myocardial infarction and are related to acute angulation and compression of the artery at its origin or along its course. ${ }^{49} 50$

\section{Management}

Due to the wide range of aetiologies diagnostic coronary angiography should be performed in all cases to establish the cause of infarction and guide therapy.

\section{Thrombolysis}

Successful thrombolysis in hypercoagulable states has been reported in the literature. ${ }^{51}$ In spasm induced myocardial infarction such as with cocaine, thrombolysis should be given if there is not a prompt resolution in symptoms and ST segment changes after giving adequate doses of vasodilators (nitrates and calcium channel blockers).

\section{Angioplasty}

There are also reports of successful percutaneous transluminal coronary angioplasty (PTCA) with or without coronary artery stenting in the antiphospholipid syndrome. ${ }^{52}$ In those patients with myocardial infarction secondary to accelerated premature atherosclerosis, early intervention with primary angioplasty has an improved outcome over thrombolysis. ${ }^{53}$ PTCA and stenting should be considered in spontaneous coronary artery dissection and myocardial bridging. ${ }^{40} 46$

\section{Antiplatelet drugs and anticoagulation}

Aspirin is recommended in most cases. Anticoagulation should be considered in the nephrotic syndrome if serum albumin is less than $20 \mathrm{~g} / \mathrm{l} \cdot{ }^{11}$ In Hughes' syndrome long term anticoagulation is needed following an infarct and the international normalised ratio should be kept above 3 .

\section{$\beta$-Blockers}

These drugs are best avoided in cocaine or amphetamine induced spasm leading to myocardial infarction as there is a potential risk of unopposed $\alpha_{1}$-adrenergic action with worsening coronary spasm.

\section{Authors' affiliations}

S Osula, R S Hornung, Aintree Cardiac Centre, University Hospital Aintree, Liverpool, UK

G M Bell, Department of Renal Medicine, Royal Liverpool University Hospital, UK

\section{REFERENCES}

1 Fujimura O, Gulamhusein S. Acute myocardial infarction: thrombotic complications of nephrotic syndrome. Can J Cardiol 1987;3:267-9.

2 Hamsten A, Norberg R, Bjorkholm M, et al. Antibodies to cardiolipin in young survivors of myocardial infarction: an association with recurrent cardiovascular events. Lancet 1986;i:113-16.

3 Manzar KJ, Padder FA, Conrad AR, et al. Acute myocardial infarction with normal coronary artery: a case report and review of literature. Am J Med Sci 1997:314:342-5.

4 Penny WJ, Colvin BT, Brooks N. Myocardial infarction with normal coronary arteries and factor XII deficiency. Br Heart J 1985; 53:230-4.
5 Agirbasli MA, Hansen DE, Byrd BF. Resolution of vegetations with anticoagulation after myocardial infarction in primary antiphospholipid syndrome. J Am Soc Echocardiogr 1997; 10:877-80.

6 Simpsons RW, Edwards WD. Pathogenesis of cocaine induced ischaemic heart disease. Autopsy findings in a 21 -year old man. Arch Pathol Lab Med 1986;1 10:479-84.

7 Ross GS, Bell J. Myocardial infarction associated with inappropriate use of cocaine for treating epistaxis. Am J Emerg Med 1992;10:219-22.

8 Williams MJA, Restieaux NJ, Low CJS. Myocardial infarction in young people with normal coronary arteries. Heart 1998;79:191-4.

9 Moreyra AE, Kostis JB, Passannante AJ, et al. Acute myocardial infarction in patients with normal coronary arteries after acute ethanol intoxication. Clin Cardiol 1982;5:425-30.

10 Huang CN, Wu DJ, Chen KS. Acute myocardial infarction caused by transnasal inhalation of amphetamine. Jpn Heart J 1993;34:815-8.

11 Fahal IH, McClelland P, Hays CRM, et al. Arterial thrombosis in the nephrotic syndrome. Postgrad Med J 1994;70:905-9.

12 Kendal AG, Loohmann RC, Dossetor JB. Nephrotic syndrome: a hypercoagulable state. Arch Intern Med 1971;127:1021-7.

13 Takeda Y. Chen A. Fibrinogen metabolism and distribution in patients with the nephrotic syndrome. J Lab Clin Med 1967;70:678-85.

14 Andrassy K, Ritz E, Bommer J. Hypercoagulablility in the nephrotic syndrome. Klin Wochenschr 1980;58:1029-36.

15 Scheinman KI, Stiehm ER. Fibrinolytic studies in the nephrotic syndrome. Pediatr Res 1971;5:206-12.

16 Camrron JS. Coagulation and thromboembolic complications in the nephrotic syndrome. Adv Nephrol 1984:13:75-114.

17 Simpson HC, Mann JI, Meade IW, et al. Hypertriglyceridaemia and hypercoagulability. Lancet 1983;i:786-90.

18 Bellomo R, Atkins RC. Membranous nephropathy and thromboembolism is prophylactic anticoagulation waranted? Nephron 1993;68:157-66.

19 Remuzzi G, Mecca G, Marchest D, et al. Platelet hyperaggregability and the nephrotic syndrome. Thromb Res 1979;16:345-54.

20 Cavalho A, Colman R, Lees R. Platelet function in hyperlipoproteinemia. N Engl J Med 1974;290:434-9

21 Hughes GR. Thrombosis, abortion, cerebral disease and the lupus anticoagulant. BM 1983;287:1088-9.

22 Vaarala $\mathrm{O}$. Antiphospholipid antibodies and atherosclerosis. Lupus 1996;5:442-7.

23 Vaarala $O$, Puurunen $M$, Manttari $M$, et al. Antibodies to prothrombin imply a risk of myocardial infarction in middle-aged men. Thromb Haemost 1996;75:456-9.

24 Jouhikainen T, Pohjola-Sintonen S, Stephansson E. Lupus anticoagulant and cardiac manifestations in systemic lupus erythematosus. Lupus 1994;3:167.

25 Khamashta MA, Cervera R, Asherson RA, et al. Association of antibodies against phospholipids with heart valve disease in systemic lupus erythromatosus. Lancet 1990;335:1541-4.

26 Espanola-Zavaleta N, Vargas-Barron J, Colmenares-Galvis T, et al. Echocardiographic evaluation of patients with primary antiphospholipid syndrome. Am Heart J 1999;137:973-8.

27 Evans SM, Brittenden J, Adam DJ, et al. Vascular surgical society of great Britain and Ireland: prevalence and significance of thrombophilia in patients with intermittent claudication. Br J Surg 1999;86:702-3.

28 Cuadrado MJ, Mujic F, Munoz E, et al. Thrombocytopenia in the antiphospholipid syndrome. Ann Rheum Dis 1997;56:194-6.

29 Reverter JC, Tassies D, Font J, et al. Effects of human monoclonal anticardiolipin antibodies on platelet function and on tissue factor expression on monocytes. Arthritis Rheum 1998:41:1420-7.

30 Harats D, George J, Levy Y, et al. Atheroma: links with antiphosoholipid antibidies, Hughes syndrome and lupus. Q J Med 1999;92:57-9.

31 Vaaral O. Antibodies to oxidised LDL. Lupus 2000;9:202-5.

32 Castro VJ, Nacht R. Cocaine-induced bradyarrhythmia: an unsuspected cause of syncope. Chest 2000;117:275-7.

33 Pitts WR, Lange RA, Cigarroa JE, et al. Cocaine-induced myocardial ischaemia and infarction. Prog Cardiovasc Dis 1997;40:65-76.

34 Flores ED, Lange RA, Cigarroa JE, et al. Effect of cocaine on coronary artery dimensions in atherosclerotic coronary artery disease: enhanced vasoconstriction at sites of significant stenoses. J Am Coll Cardiol 1990;16:74.

35 Kolodgie FD, Virmani R, Rice HE, et al. Intravenous cocaine accelerates atherosclerosis in cholesterol-fed New Zealand white rabbits, abstracted. J Am Coll Cardiol 1990;15(suppl A):217A.

36 Dressler FA, Malekzadeh S, Roberts WC. Quantitative analysis of amount of coronary arterial narrowing in cocaine addicts. Am J Cardiol 1990;65:303-8.

37 Connolly DL, Dardas PS, Crowley JJ, et al. Acute coronary embolism complicating aortic valve endocarditis treated with streptokinase and aspirin. A case report. J Heart Valve Dis 1994;3:245-6.

38 Mathew J, Addai T, Anand A. Clinical features, site of involvement, bacteriologic findings, and outcome of infective endocarditis in intravenous drug users. Arch Intern Med 1995;155:1641-8.

39 Valtonen V, Kuikka A, Syrjanen J. Thrombo-embolic complications in bacteraemic infections. Eur Heart J 1993;14(suppl K):20-3.

40 Klues HG, Schwarz ER, vom Dahl J, et al. Disturbed intracoronary hemodynamics in myocardial bridging: early normalization by intracoronary stent placement. Circulation 1997;96:2905-13

41 Mc Gill HC, McMahan CA, Zieske AW, et al. Association of coronary heart disease risk factors with microscopic qualities of coronary atherosclerosis in youth. Circulation 2000;102:375.

42 Vuorio AF, Kontula K, Turtola $\mathrm{H}$. Post mortem molecularly defined familial hypercholesterolemia and sudden cardiac death of young men. Forensic Sci Int 1999;106:87-92. 
43 Booth GL, Wang EE. Preventive health care, 2000 update: screening and management of hyperhomocysteinemia for the prevention of coronary artery disease events. The Canadian Task Force on Preventive Health Care. Can Med Assoc J 2000;163:21-9.

44 Horejsi B, Ceska R. Apolipoproteins and atherosclerosis. Apolipoprotein $E$ and apolipoprotein(a) as candidate genes of premature development of atherosclerosis. Physiol Res 2000;49(suppl 1):S63-9.

45 Gaeta G, De Michele M, Cuomo S. Arterial abnormalities in the offspring of patients with premature myocardial infarction. N Engl J Med 2000:343:840-6.

46 Vale PR, Baron DW. Coronary artery stenting for spontaneous coronary artery dissection: a case report and review of the literature. Cathet Cardiovasc Diagn 1998;45:280-6.

47 Lee BW, Tay JS, Yip WC, et al. Kawasaki syndrome in Chinese children. Ann Trop Paediatr 1989;9:147-51.

48 Dagalp Z, Pamir G, Alpman A, et al. Coronary artery aneurysms. Report of two cases and review of literature. Angiology 1996;47:197-201.
49 Hamamichi Y, Okada E, Ichida F. Anomalous origin of the main stem of the left coronary artery from the non-facing sinus of valsalva associated with sudden death in a young athlete. Cardiol Young 2000;10:147-9.

50 Taylor AJ, Byers JP, Cheitlin MD, et al. Anomalous right or left coronary artery from the contralateral coronary sinus: "high-risk" abnormalities in the initial coronary artery course and heterogeneous clinical outcomes. Am Heart J 1997; 133:428-35.

51 Ho YL, Chen MF, Wu CC, et al. Successful treatment of acute myocardial infarction by thrombolytic therapy in a patient with primary antiphospholipid antibody syndrome. Cardiology 1996;87:354-7.

52 Takeuchi S, Obayashi T, Toyama J. Primary antiphospholipid syndrome with acute myocardial infarction recanalised by PTCA. Heart 1998;79:96-8.

53 Holmes DR, White HD, Topol EJ, et al. Effect of age on outcome with primary angioplasty versus thrombolysis. J Am Coll Cardiol 1999;33:412-9. 